\title{
Activation of Prejunctional P2x2/3 Heterotrimers by ATP Enhances the Cholinergic Tone in Obstructed Human Urinary Bladders
}

\author{
M. Silva-Ramos, ${ }^{1}$ I. Silva,${ }^{1}$ M. Faria, ${ }^{2}$ F. Ferreirinha, and P. Correia-de-Sá
}

Laboratório de Farmacologia e Neurobiologia and Center for Drug Discovery and Innovative Medicines (MedlnUP), Instituto de Ciências Biomédicas de Abel Salazar (ICBAS), Universidade do Porto, Porto, Portugal (M.S.-R., I.S., M.F., F.F., P.C.-S.); and Serviço de Urologia, Centro Hospitalar Universitário do Porto (CHUP), Porto, Portugal (M.S.-R.)

Received July 19, 2019; accepted October 15, 2019

\section{ABSTRACT}

The objective of this study was to investigate the role of ATP in cholinergic neurotransmission in the urinary bladder of control men and of patients obstructed as a result of benign prostatic hyperplasia (BPH). Human detrusor samples were collected from 41 patients who submitted to transvesical prostatectomy resulting from $\mathrm{BPH}$ and 26 male organ donors. The release of $\left[{ }^{3} \mathrm{H}\right]$ acetylcholine $\left(\left[{ }^{3} \mathrm{H}\right] \mathrm{ACh}\right)$ was evoked by electrical field stimulation (10 Hz, 200 pulses) in urotheliumdenuded detrusor strips. Myographic recordings were performed to test detrusor strip sensitivity to ACh and ATP. Nerve-evoked $\left[{ }^{3} \mathrm{H}\right] \mathrm{ACh}$ release was 1.5-fold higher in detrusor strips from $\mathrm{BPH}$ patients compared with controls. This difference was abolished after desensitization of ionotropic P2X1-3 receptors with an ATP analog, $\alpha, \beta$-methylene ATP (30 $\mu \mathrm{M}$, applied for 15 minutes). TNP-ATP (10 nM, a preferential P2X2/3 antagonist) and A317491 (100 nM, a selective P2X3 antagonist) were about equipotent in decreasing nerveevoked $\left[{ }^{3} \mathrm{H}\right] \mathrm{ACh}$ release in control detrusor strips, but the selective P2X1 receptor antagonist NF023 (3 $\mu \mathrm{M})$ was devoid of effect. The inhibitory effect of TNP-ATP $(10 \mathrm{nM})$ increased from $27 \% \pm 9 \%$ to $43 \% \pm 6 \%$ in detrusor strips of $\mathrm{BPH}$ patients, but the effect of $\mathrm{A} 317491(100 \mathrm{nM})\left[{ }^{3} \mathrm{H}\right] \mathrm{ACh}$ release unaltered $(20 \% \pm 2 \%$ vs. $24 \% \pm 4 \%)$. The amplitude of ACh (0.1-100 $\mu \mathrm{M})$-induced myographic recordings decreased, whereas sensitivity to ATP $(0.01-3 \mathrm{mM})$ increased in detrusor strips from $\mathrm{BPH}$ patients. Besides the well characterized P2X1 receptor-mediated contractile activity of ATP in pathologic human bladders, we show here for the first time that cholinergic hyperactivity in the detrusor of $\mathrm{BPH}$ patients is facilitated by activation of ATP-sensitive P2X2/3 heterotrimers.

\section{SIGNIFICANCE STATEMENT}

Bladder outlet obstruction often leads to detrusor overactivity and reduced bladder compliance in parallel to atropineresistant increased purinergic tone. Our data show that P2X1 purinoceptors are overexpressed in the detrusor of patients with benign prostatic hyperplasia. Besides the $\mathrm{P} 2 \mathrm{X} 1$ receptormediated detrusor contractions, ATP favors nerve-evoked acetylcholine release via the activation of prejunctional $\mathrm{P} 2 \mathrm{X} 2 / 3$ excitatory receptors in these patients Thus, our hypothesis is that manipulation of the purinergic tone may be therapeutically useful to counteract cholinergic overstimulation in obstructed patients.
This research was partially supported by Fundação para a Ciência e a Tecnologia (FCT, FEDER funding, projects [PTDC/SAU-OSM/104369/2008], [REEQ/1168/ SAU/2005], [REEQ/1264/SAU/2005], [Pest-OE/SAU/UI215/2014], [UID/BIM/4308/ 2016], and [UID/BIM/4308/2019]), Associação Portuguesa de Urologia (APU) and University of Porto/Caixa Geral de Depósitos (Investigação Científica na PréGraduação). The funders had no role in study design, data collection and analysis, decision to publish, or preparation of the manuscript. I.S. received a $\mathrm{PhD}$ Studentship from FCT [SFRH/BD/88855/2012].

${ }^{1}$ M.S.-R. and I.S. contributed equally to this work.

${ }^{2}$ M. Faria: Born in July 21, 1969; deceased May 22, 2018.

https://doi.org/10.1124/jpet.119.261610.

\section{Introduction}

Bladder outlet obstruction (BOO) often leads to detrusor overactivity (DO) and reduced bladder compliance causing urine storage symptoms (Mirone et al., 2007). DO is detected in about half to two-thirds of patients with diagnosed benign prostatic hyperplasia (BPH) and has a huge impact on patients' quality of life (Mirone et al., 2007). The prevalence of DO decreases by $50 \%$ after prostatic surgery (Abrams et al., 1979), suggesting that it may be caused, at least in part, by BOO. Notwithstanding this, the mechanisms underlying DO caused by obstruction are largely unknown (Andersson, 2003). On the other hand, subsequent failure of the detrusor to

ABBREVIATIONS: A317491, 5-[[[(3-phenoxyphenyl) methyl] [(1S)-1,2,3,4-tetrahydro-1-naphthalenyl] amino] carbonyl]-1,2,4-benzenetricarboxylic acid sodium salt hydrate; ARL67156, 6-N,N-diethyl-D- $\beta, \gamma$-dibromomethylene ATP trisodium salt; BOO, bladder outlet obstruction; BPH, benign prostatic hyperplasia; DAPI, 4',6-diamidino-2-phenylindole; DO, detrusor overactivity; DU, detrusor underactivity; EFS, electrical field stimulation; $\left[{ }^{3} \mathrm{H}\right] \mathrm{ACh},\left[{ }^{3} \mathrm{H}\right]$ acetylcholine; $\alpha, \beta$-MeATP, $\alpha, \beta$-methylene ATP; NF023, 8,8'-[carbonylbis(imino-3,1-phenylenecarbonylimino)]bis-1,3,5-naphthalenetrisulphonic acid hexasodium salt; NTPDases, ecto-nucleoside triphosphate diphosphohydrolases; PPADS, pyridoxal phosphate-6-azo (benzene2,4-disulfonic acid) tetrasodium salt hydrate; TNP-ATP, $2^{\prime}, 3^{\prime}-O-(2,4,6$-trinitrophenyl)adenosine-5'-triphosphate tetra(triethylammonium) salt. 
contract may appear at a later stage of obstructed bladder dysfunction. Detrusor underactivity (DU) is defined by the International Continence Society as a contraction of reduced strength and/or duration resulting in prolonged and incomplete emptying of the bladder. Although a bit forgotten from the scientific literature, this aspect of the bladder physiology is gaining increased attention (van Koeveringe et al., 2011). DU has been associated with age (Van Mastrigt and Rollema, 1992) and its prevalence is thought to be increasing owing to ageing of the population. Until now, the basis of treatment has been bladder catheterization and no effective therapeutic drug is yet available.

Increasing evidence supports a role for purines in the pathophysiology of DO and in bladder changes resulting from $\mathrm{BOO}$ (Burnstock, 2011). In humans, normal detrusor contraction is exclusively under cholinergic control, since it is fully blocked by atropine (Fry et al., 1999). However, in hypertrophic bladders secondary to prostatic obstruction atropine-resistant contractions appear (Sjögren et al., 1982; Bayliss et al., 1999), and they have been attributed to ATP because they are fully blocked by desensitization of ionotropic $\mathrm{P} 2 \mathrm{X}$ receptors with the enzymatically stable ATP analog $\alpha, \beta$-methylene ATP (Bayliss et al., 1999). However, there are gaps in our knowledge regarding the purinergic control of the bladder function, mostly because the balance between the cholinergic and purinergic components varies significantly among species (Wust et al., 2002; Ford et al., 2006) and, thus, when comparing rodents to humans, the observed changes in response to bladder obstruction are unpredictable. For instance, the ATP-mediated component is already relevant in normal bladder contractions in rodents and rabbits, but it is not exaggerated in obstructed (Banks et al., 2006) and neurogenic (Yokota and Yamaguchi, 1996) bladders, rendering these models less suitable for studying (purinergic) detrusor changes after BOO.

The prominent role of ATP in the bladder of men with BPH has been essentially attributed to its ability to increase detrusor smooth muscle tension (Bayliss et al., 1999). The mechanism underlying the increased ATP activity in the bladders of obstructed patients has been attributed to decreased ectoATPase activity (Harvey et al., 2002) leading to reduced inactivation of the nucleotide and, thus, increased lifetime of ATP released by the urothelium and cholinergic bladder efferents (Silva-Ramos et al., 2015). In addition, our group demonstrated that the release of ATP is also higher in urothelium-denuded detrusor strips from $\mathrm{BPH}$ patients compared with age-matched controls (Silva-Ramos et al., 2010, 2015).

Besides its action as a cotransmitter in several myoneural junctions, ATP can also act as a neuromodulator controlling the release of acetylcholine $(\mathrm{ACh})$ and other neurotransmitters (Ribeiro et al., 1996; Duarte-Araújo et al., 2009; BarrosBarbosa et al., 2016, 2018; Vieira et al., 2017). The neuromodulatory role of ATP has been demonstrated in the bladders of rats and pigs (King et al., 1997; D’Agostino et al., 2012). ATP favored cholinergic neurotransmission in the pig detrusor via the activation of presynaptic P2X3 receptors, and the facilitatory role of the nucleotide was further enhanced by the ecto-ATPase inhibitor ARL67156 (D'Agostino et al., 2012). Recently, we showed that pathologic deficits in ATP inactivation are observed in the bladder of BPH patients, leading to deficient extracellular adenosine formation and cholinergic hyperactivity as a consequence of a loss of $\mathrm{A}_{1}$-receptormediated neural inhibitory tone (Silva-Ramos et al., 2015).
To our knowledge, no study has so far been undertaken to explore the presynaptic repercussion of surplus ATP accumulation on $\mathrm{ACh}$ release from cholinergic nerves in obstructed human detrusor samples compared with individuals with normal bladder function. The results obtained may provide novel targets for therapeutic intervention in obstructed patients with detrusor overactivity and/or underactivity.

\section{Materials and Methods}

Human Detrusor Samples. Samples of human detrusor were collected from the bladder domes of 41 patients with BOO owing to $\mathrm{BPH}$ during transvesical prostatectomy (aged $71 \pm 7$ years) and from 26 male cadaveric organ donors without known lower urinary tract pathology (aged $50 \pm 17$ years). BOO and prostate enlargement were confirmed by uroflowmetry and ultrasonography, respectively. Collected samples were immediately placed at $4-6^{\circ} \mathrm{C}$ in mannitol transplantation solution at $400 \mathrm{mOsm} / \mathrm{kg}$ (M-400) not supplemented with ATP or adenosine (230 mM mannitol, $15 \mathrm{mM} \mathrm{KH}_{2} \mathrm{PO}_{4}, 43 \mathrm{mM}$ $\mathrm{K}_{2} \mathrm{HPO}_{4} \cdot 3 \mathrm{H}_{2} \mathrm{O}, 15 \mathrm{mM} \mathrm{KCl}$, and $\left.10 \mathrm{mM} \mathrm{NaHCO} 3, \mathrm{pH} 7.4\right)$ and transported to the laboratory. Experiments were performed within the first 24 hours after collection, which corresponds to the tissue viability window. This study and all its procedures were approved by the Ethics Committees of CHUP and ICBAS-UP and were authorized by the National Transplantation Committee. All BPH patients signed an informed consent approved by the Ethics Committee of CHUP for use of the biologic material. Regarding deceased organ donation, the legal frame work allows the "Presumed Consent," stating that residents in Portugal are consenting donors unless the individual previously objected during his or her life. The investigation conformed to the principles outlined in The Code of Ethics of the World Medical Association (Declaration of Helsinki).

Quantification of $\left[{ }^{3} \mathbf{H}\right] \mathbf{A C h}$ Release. Human detrusor strips (approx. $1.5 \times 5 \mathrm{~mm}$ ) were mounted in vertical superfusion organ baths. The procedures used for labeling the preparations and measuring evoked $\left[{ }^{3} \mathrm{H}\right] \mathrm{ACh}$ release followed the previously described protocol with minor modifications (Silva-Ramos et al., 2015; Silva et al., 2017). After a 30-minute equilibration period, cholinergic nerve terminals were labeled for 40 minutes with $1 \mathrm{mM}\left[{ }^{3} \mathrm{H}\right]$-choline (specific activity 2.5 $\mathrm{mCi} \cdot \mathrm{nmol}^{-1}$ ) under electrical stimulation (EFS, 1-Hz frequency, 1-millisecond pulse width). Washout of the preparations was performed during 60 minutes, by superfusion ( $15 \mathrm{ml}$ minute ${ }^{-1}$ ) with Tyrode's solution supplemented with choline uptake inhibitor hemicholinium-3 $\left(10 \mu \mathrm{mol} \cdot \mathrm{l}^{-1}\right)$. Tritium outflow was evaluated by liquid scintillation spectrometry (TriCarb2900 TR; Perkin Elmer, Boston) (\% counting efficiency: $55 \% \pm 2 \%$ ) after appropriate background subtraction, using $400-\mu \mathrm{l}$ bath samples collected automatically every 3 minutes with a fraction collector (FC203B; Gilson, France). $\left[{ }^{3} \mathrm{H}\right] \mathrm{ACh}$ release was evoked by two periods of EFS $\left(\mathrm{S}_{1}\right.$ and $\mathrm{S}_{2}, 200$ pulses of 0.5 -millisecond duration delivered at $10-\mathrm{Hz}$ frequency). Therefore, the evoked $\left[{ }^{3} \mathrm{H}\right] \mathrm{ACh}$ release was calculated by subtracting the basal tritium outflow from the total tritium outflow during the stimulation period (see e.g., Carneiro et al., 2014; Silva-Ramos et al., 2015; Silva et al., 2017).

Test drugs were added 15 minutes before $\mathrm{S}_{2}$ and were present until the end of the experiments. The change in the ratio between the evoked $\left[{ }^{3} \mathrm{H}\right] \mathrm{ACh}$ release during the two stimulation periods $\left(\mathrm{S}_{2} / \mathrm{S}_{1}\right)$ relative to that observed in control situations (in the absence of test drugs) was taken as a measure of the effect of the tested drugs.

Myographic Recordings. Detrusor muscle strips without the mucosa were mounted in 10-ml capacity perfusion chambers connected to isometric force transducers. The changes in tension were recorded continuously with a PowerLab data acquisition system (Chart 5, v.4.2; $\mathrm{AD}$ Instruments). Tissues were preloaded with $5 \mathrm{mN}$ of tension and allowed to equilibrate for 90 minutes in Tyrode's solution, at $37^{\circ} \mathrm{C}$. Contractile responses were elicited by cumulative applications of ACh $(0.1-100 \mu \mathrm{M})$ or ATP $(0.01-3 \mathrm{mM})$. Nerve-evoked contractile responses elicited by EFS trains of 5 -second duration delivered every 2 minutes at increasing 
frequencies (1-50 Hz, 1-millisecond pulse width) were also recorded in detrusor strips from control individuals and $\mathrm{BPH}$ patients; the magnitude of EFS-evoked detrusor contractions was normalized by the myographic response produced by high extracellular $\mathrm{KCl}(60 \mathrm{mM})$ in the same preparation. Dependence of EFS-induced detrusor contractile responses on generation of nerve action potentials was confirmed by blockage with tetrodotoxin $(1 \mu \mathrm{M})$ (Fig. 1, B and C).

Immunofluorescence Staining and Confocal Microscopy Observation. Detrusor samples fragments were fixed in PLP solution (paraformaldehyde $2 \%$, lysine $0.075 \mathrm{M}$, sodium phosphate 0.037 M, sodium periodate $0.01 \mathrm{M}$ ) for 16 hours at $4^{\circ} \mathrm{C}$. Fixed tissue was cryoprotected with a solution containing $20 \%$ anhydrous glycerol dissolved in $0.1 \mathrm{M}$ phosphate buffer, frozen, sectioned $(16-\mu \mathrm{m})$, and incubated with a blocking buffer solution consisting of fetal bovine serum $10 \%$, bovine serum albumin $1 \%$, Triton X-100 $0.3 \%$ in phosphate-buffered saline (PBS), for 2 hours with constant stirring. After blocking and permeabilization, samples were incubated with rabbit anti-P2X1 primary antibody (1:75; \#APR-001; Alomone, Jerusalem, Israel) diluted in the incubation buffer (fetal bovine serum 5\%, serum albumin $1 \%$, Triton X-100 $0.3 \%$ in PBS), at $4^{\circ} \mathrm{C}$, for 16 hours. After unbound primary antibody was washed away, the sections were incubated with donkey anti-rabbit IgG secondary antibody (1:1000; Alexa Fluor 488, \#A-21206; Invitrogen) in the dark for 2 hours, at room temperature. Finally, tissue samples were mounted on opticalquality glass slides using VectaShield with DAPI as mounting medium (VectorLabs) and stored in the dark at $4^{\circ} \mathrm{C}$. Observations were performed and analyzed with a laser-scanning confocal microscope (FluoView, FV1000; Olympus, Tokyo, Japan). Immunofluorescence images were quantified according to those described by Vieira et al. (2017) with minor modifications. Images were stored in TIFF format with the same resolution and subsequently analyzed with the ImageJ software version 1.46r (National Institutes of Health) to quantify the density of stained
B

A

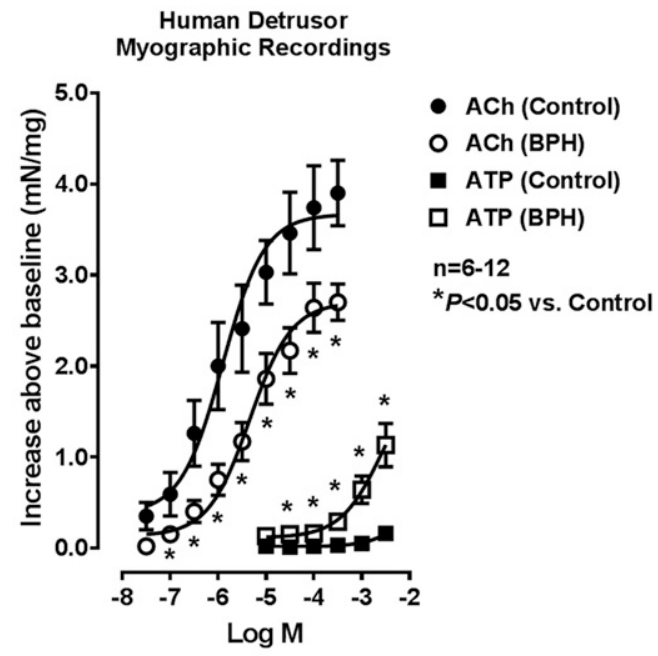

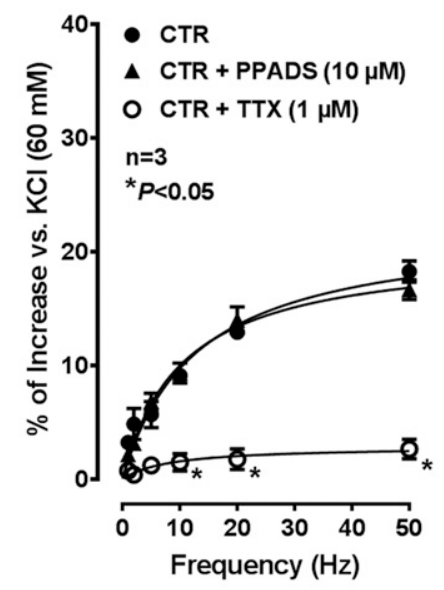

D

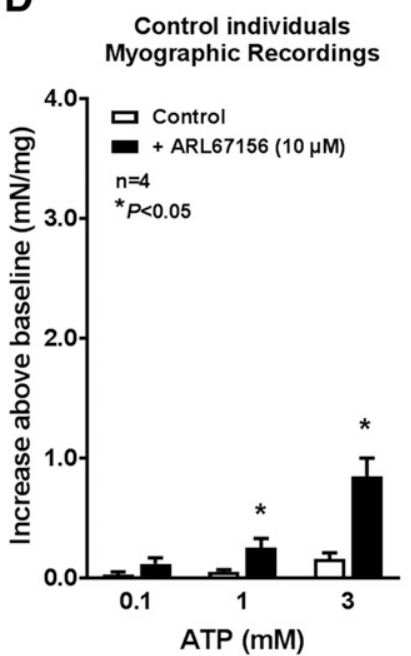

C

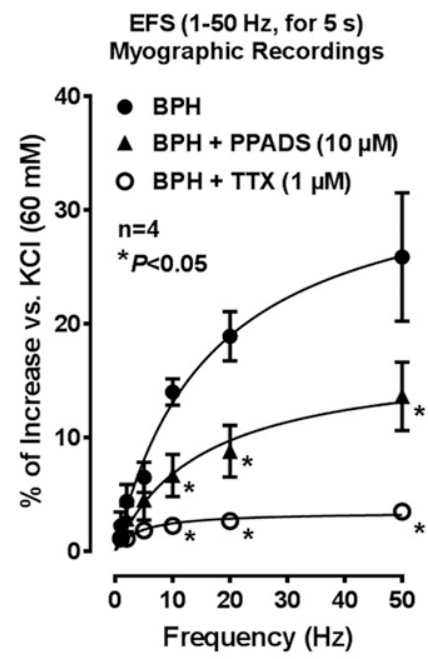

E

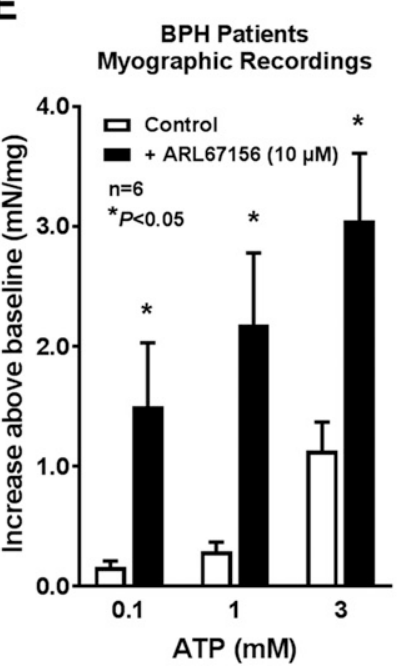

Fig. 1. (A) Contractile responses of isolated human detrusor strips from control individuals and BPH patients to ACh $(0.03-300 \mu M)$ and ATP (0.01-3 $\mathrm{mM})$. The magnitude of nerve-evoked detrusor contractions from control individuals (B) and BPH patients (C) in the absence and in the presence of the nerve action potentials blocker tetrodotoxin (TTX, $1 \mu \mathrm{M}$ ), or of the nonselective P2 purinoceptor antagonist PPADS (10 $\mu \mathrm{M})$ are also shown for comparison. Detrusor strips were stimulated with EFS trains of 5-second duration at increasing frequencies (1-50 Hz, 2-minute intertrain intervals). Drugs were added 15 minutes before starting the stimulation protocol. The magnitude of EFS-evoked detrusor contractions was normalized by the myographic response produced by high extracellular $\mathrm{KCl}(60 \mathrm{mM})$ in the same preparation. The vertical bars represent S.D. of an $n$ number of individuals and are shown when they exceed the symbol in size. $* P<0.05$ (unpaired Student's $t$-test corrected for multiple comparisons using the HolmSidak method) represent significant differences compared with control organ donors (in A) or to the absence of test drugs (in B and C), respectively. Pretreatment with the NTPDase inhibitor ARL67156 (100 $\mu \mathrm{M})$ potentiates ATP $(0.1-3 \mathrm{mM})$-induced contractions of detrusor strips isolated from control individuals (D) and BPH patients (E). Bars represent mean \pm S.D. of six individuals. ${ }^{*} P<0.05$ (unpaired Student's $t$-test corrected for multiple comparisons using the Holm-Sidak method) represent significant differences compared with the effect of ATP alone. 
P2X1 immunoreactivity of the human detrusor. Settings such as the area, the integrated density, and the mean gray value were measured systematically in all analyzed images; the background setting was the primary antibody. The values obtained were used to calculate the corrected total cryosection fluorescence (CTCF) using a formula published in http://sciencetechnblog.com/2011/05/24/measuring-cellfluorescence-using-imagejhttps://sciencetechblog.wordpress.com/2011/ 05/24/measuring-cell-fluorescence-using-imagej/.

Western Blot Analysis. Human detrusor strips without the mucosa were homogenized in radioimmunoprecipitation assay buffer (Tris-HCl $25 \mathrm{mM}, \mathrm{pH} 7.6, \mathrm{NaCl} 150 \mathrm{mM}$, sodium deoxycholate 1\%, Triton-X-100 1\%, SDS 0.1\%, EDTA $5 \mathrm{mM}$ ) plus a protease inhibitor cocktail. Protein content of the samples was evaluated using the BCA protein assay kit according to the manufacturer's instructions (Pierce, Rockford, IL). Samples were solubilized in SDS reducing buffer (Tris$\mathrm{HCl} 125 \mathrm{mM}$, pH 6.8, SDS 4\%, bromophenol blue $0.005 \%$, glycerol $20 \%$, and 2-mercaptoethanol $5 \%$ ) at $70^{\circ} \mathrm{C}$ for 10 minutes, subjected to electrophoresis in 10\% SDS-polyacrylamide gels, and electrotransferred onto polyvinylidene difluoride membranes (MilliPore, MA). Protein load was $65 \mu \mathrm{g}$. The membranes were then blocked in Trisbuffered saline (in millimolars: Tris- $\mathrm{HCl} 10, \mathrm{pH} 7.6, \mathrm{NaCl} 150$ ) containing Tween $200.05 \%$ and bovine serum albumin 5\%, and subsequently incubated with P2X1 primary antibody from Alomone (host species: rabbit, 1:200, APR-001) in the above blocking buffer overnight at $4^{\circ} \mathrm{C}$. Membranes were washed three times for 10 minutes in Tris-buffered saline/Tween-20 and incubated with horseradish peroxidase-conjugated secondary antibody (1:25,000; Abcam, Cambridge, UK) for 1 hour at room temperature. For normalization purpose, membranes were incubated with mouse anti-GAPDH (EC 1.2.1.12) primary antibody from Santa Cruz (1:200, SC-32233; Dallas, TX) following the procedures described above. Membranes were washed three times for 10 minutes, and the antigen-antibody complexes were visualized with the Immun-Star WesternC Chemiluminescent Kit using the ChemiDoc MP imaging system (Bio-Rad Laboratories, Hercules, CA).

Drugs and Solutions. Hemicholinium-3, choline chloride, and pyridoxal phosphate-6-azo (benzene-2,4-disulfonic acid) tetrasodium salt hydrate (PPADS) were from Sigma (St. Louis, MO); ATP, $\alpha, \beta$-methylene ATP, $2^{\prime}, 3^{\prime}$-O-(2,4,6-trinitrophenyl)adenosine-5' triphosphate tetra(triethylammonium) salt (TNP-ATP), 6-N,Ndiethyl-D- $\beta, \gamma$-dibromomethylene ATP trisodium salt (ARL67156), 5-[[[(3-phenoxyphenyl) methyl] [(1S)-1,2,3,4-tetrahydro-1-naphthalenyl] amino] carbonyl]-1,2,4-benzenetricarboxylic acid sodium salt hydrate (A317491), 8,8' -[carbonylbis(imino-3,1-phenylenecarbonylimino)]bis-1,3,5-naphthalene-trisulphonic acid hexasodium salt (NF023), and tetrodotoxin were obtained from Tocris Bioscience (Bristol, UK); $\left[\right.$ methyl ${ }^{3} \mathrm{H}$ ]choline chloride (in ethanol, 85.5 Ci. $\mathrm{mmol}^{-1}$ ) was from Perkin Elmer; PPADS was made up as $3 \mathrm{mmol} \cdot \mathrm{l}^{-1}$, and TNP-ATP was made up as $10 \mathrm{mmol} \cdot \mathrm{l}^{-1}$ stock solution in distilled water. A317491 was prepared in dimethyl sulfoxide. All the other compounds were dissolved in Tyrode's solution. PPADS was kept protected from light to prevent photodecomposition. All stock solutions were stored as frozen aliquots at $-20^{\circ} \mathrm{C}$. Dilutions of these stock solutions were made daily and appropriate solvent controls were done. No statistically significant differences between control experiments made in the absence or in the presence of the solvents at the maximal concentrations used $(0.5 \% \mathrm{v} / \mathrm{v})$ were observed.

Presentation of Data and Statistical Analysis. Results are expressed as mean \pm S.D., with $n$ indicating the number of individuals used for a particular set of experiments. Only one experimental procedure (e.g., agonist in the absence and in the presence of the antagonist) was performed per individual. Statistical analysis of data were carried out using Graph Pad Prism 7.04 for Windows software (La Jolla). Unpaired Student's $t$-test corrected by the HolmSidak method for multiple comparisons was used in most circumstances. Two-way analysis of variance (ANOVA) followed by the Sidak's multicomparison test was used only if $\mathrm{F}$ was significant and there was no variance inhomogeneity. Pearson $r$ was used to test correlations. $P<0.05$ (two-tailed) values were considered statistically significant.

\section{Results}

Contractile Responses of Urothelium-Denuded Detrusor Strips from Control Organ Donors and BPH Patients to ACh and ATP. Bath application of acetylcholine (ACh, 0.03-300 $\left.\mu \mathrm{M} ; \operatorname{LogEC}_{50}=-5.91\right)$ concentration-dependently increased smooth muscle tension in the detrusor of control organ donors (Fig. 1A). However, cholinergic-induced detrusor contractions ( $\operatorname{LogEC} \mathrm{E}_{50}=-5.34$ ) had a smaller magnitude $(P<0.05)$ in samples from patients with $\mathrm{BOO}$ owing to $\mathrm{BPH}$ (Fig. 1A). For instance, the contractile activity of $\mathrm{ACh}$ $(100 \mu \mathrm{M})$ decreased $(P<0.05)$ from $3.74 \pm 0.46(n=12)$ to $2.64 \pm 0.27 \mathrm{mN} / \mathrm{mg}(n=12)$ in control individuals and $\mathrm{BPH}$ patients, respectively. To exclude bias owing to age difference between $\mathrm{BPH}$ patients ( $71 \pm 7$ years) and control organ donors (50 \pm 17 years), we performed a correlation analysis between age and the magnitude of ACh $(10 \mu \mathrm{M})$-induced contractions; the Pearson's $r$ value obtained was -0.048 , which did not reach statistical significance $(P=0.810)$. In view of this, ageing does not seem to contribute, on its own, to decrease the sensitivity of detrusor smooth muscle fibers to ACh in obstructed bladders.

ATP (0.01-3 mM) was virtually devoid of effect on detrusor strips from control individuals (Fig. 1A), but the nucleotide concentration-dependently increased $(P<0.05)$ the contractile tension of urothelium-denuded detrusor strips isolated from $\mathrm{BPH}$ patients. At the maximal concentration tested, ATP (3 mM)-induced detrusor contractions reached $43 \%(1.13 \pm$ $0.24 \mathrm{mN} / \mathrm{mg}, n=6$ ) of the effect caused by $100 \mu \mathrm{M}$ ACh in $\mathrm{BPH}$ patients and this value was significantly $(P<0.05)$ higher than that observed in the strips from control individuals $(0.16 \pm 0.05 \mathrm{mN} / \mathrm{mg}, n=6)$ (Fig. 1A). It is also worth noting that the P2 purinoceptor-mediated component of nerveevoked detrusor contractions was more evident in preparations from $\mathrm{BPH}$ patients than in control individuals. This was noticed because the blocking effect of PPADS (10 $\mu \mathrm{M}$, a nonselective P2 purinoceptor antagonist) only became apparent in detrusor strips from BPH patients (Fig. 1C), whereas this drug was devoid of effect on nerve-evoked detrusor contractions from control organ donors (Fig. 1B).

At the same concentration, PPADS $(10 \mu \mathrm{M})$ prevented $(P<0.05)$ the contractile effect of ATP $(0.03-3 \mathrm{mM})$ on detrusor strips from BPH patients. Prevention of ATP (0.03-3 mM)-induced detrusor contractions by PPADS $(10 \mu \mathrm{M})$ was mimicked by selective blockage of the P2X1 receptor with NF023 (3 $\mu \mathrm{M})$, but the same was not observed with TNP-ATP (10 nM, a preferential P2X2/3 antagonist) and A317491 (100 nM, a selective P2X3 antagonist) (Fig. 2).

The competitive inhibitor of human NTPDase1 $\left(K_{i} 11 \pm 3 \mu \mathrm{M}\right)$ and NTPDase3 $\left(K_{\mathrm{i}} 18 \pm 4 \mu \mathrm{M}\right)$, ARL67156 (100 $\left.\mu \mathrm{M}\right)$, significantly $(P<0.05)$ potentiated the contractile activity of ATP (0.1-3 mM) on detrusor strips isolated from both control individuals (Fig. 1D) and BPH patients (Fig. 1E), without affecting the magnitude of $\mathrm{ACh}(0.03-300 \mu \mathrm{M})$-induced detrusor contractions (data not shown). The magnitude of ARL67156 $(100 \mu \mathrm{M})$ potentiation of ATP-induced detrusor contractions was higher in $\mathrm{BPH}$ patients. Overall, these results confirm our previous assumption that NTPDase1/CD39 is mainly responsible for ATP/ADP enzymatic inactivation in the human detrusor (Silva-Ramos et al., 2015) and suggest that sensitivity to changes in the hydrolytic activity of ecto-nucleoside triphosphate 
$A_{i}$

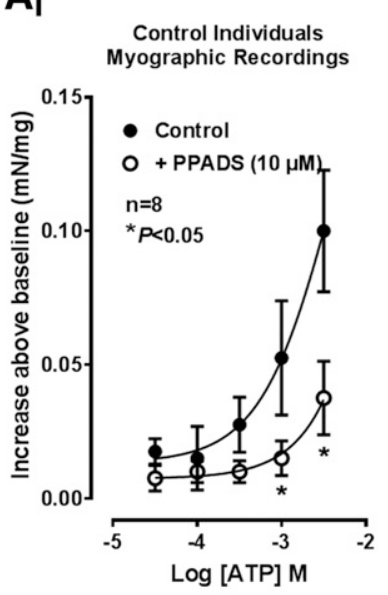

$B_{i}$

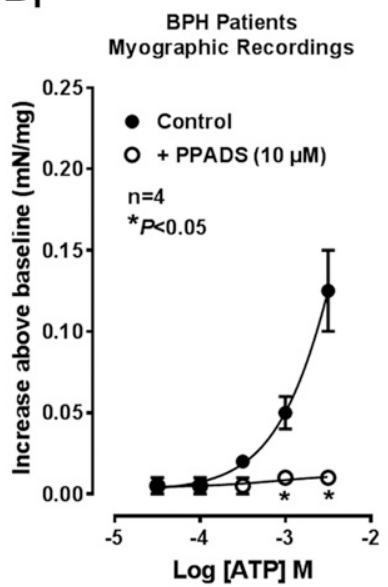

$A_{i i}$

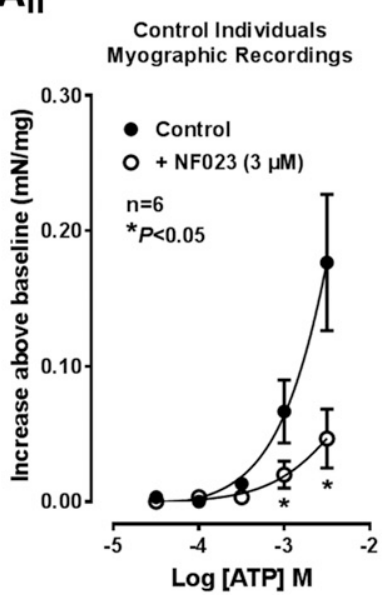

$B_{i i}$

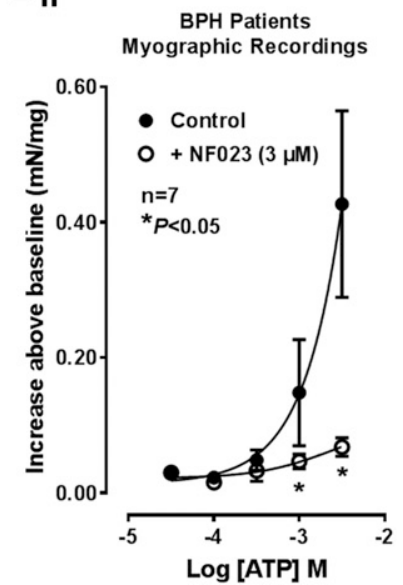

$A_{\text {iii }}$

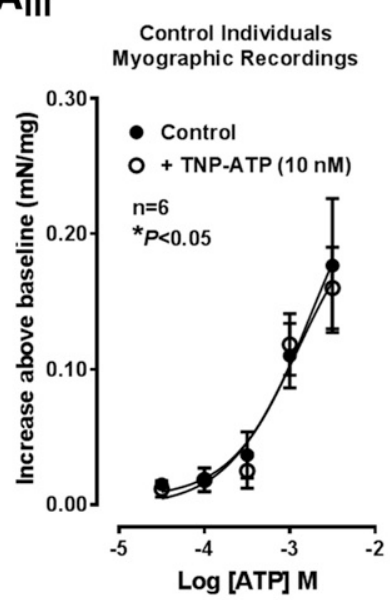

$B_{\text {iii }}$

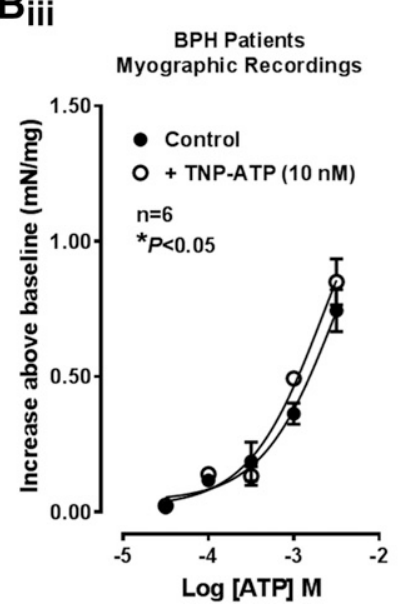

$A_{\text {iv }}$

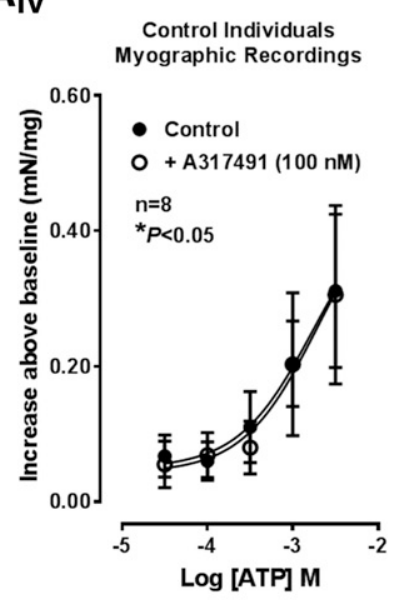

$B_{\text {iv }}$

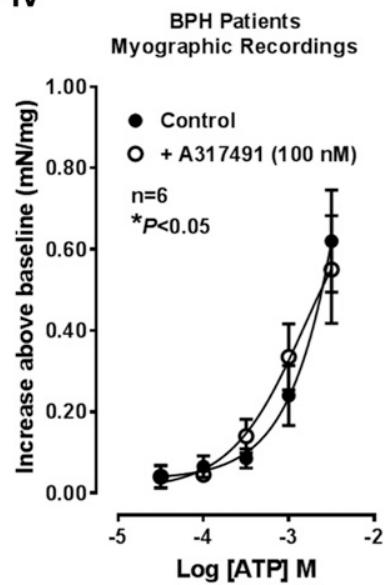

Fig. 2. ATP (0.01-3 mM)-induced contractile responses of isolated human detrusor strips from (A) control individuals and (B) BPH patients in the absence and in the presence of PPADS $(10 \mu \mathrm{M})$, NF023 $(3 \mu \mathrm{M})$, TNP-ATP $(10 \mathrm{nM})$, and A317491 (100 nM). The vertical bars represent S.D. of an $n$ number of individuals and are shown when they exceed the symbol in size. $* P<0.05$ (unpaired Student's $t$-test corrected for multiple comparisons using the Holm-Sidak method) represent significant differences compared with the effect of ATP alone.

diphosphohydrolases (NTPDases) by ARL67156 (100 $\mu \mathrm{M})$ has a higher impact in the detrusor of obstructed patients.

The P2X1 Receptor Is Overexpressed in Detrusor Smooth Muscle Fibers of BPH Patients Compared with Control Individuals. The presence of $\mathrm{P} 2 \mathrm{X} 1$ receptors in the human detrusor was demonstrated by immunofluorescence confocal microscopy (Fig. 3A). The staining pattern indicates that $\mathrm{P} 2 \mathrm{X} 1$ receptors are located on the plasma membrane of detrusor smooth muscle fibers (Fig. $3 \mathrm{~A}_{\mathrm{i}}$; see also Elneil et al., 2001). Corrected total cryosection fluorescence quantification (Fig. $3 \mathrm{~A}_{\mathrm{ii}}$ ) and Western blot analysis (Fig. 3B) demonstrated that $\mathrm{P} 2 \mathrm{X} 1$ receptors were overexpressed in detrusor samples from $\mathrm{BPH}$ patients compared with control individuals. Overexpression of the $\mathrm{P} 2 \mathrm{X} 1$ receptor protein was in agreement with previous RT-PCR studies (O'Reilly et al., 2001) and may explain amplification of bladder contractions caused by ATP in BPH patients compared with control individuals.

Endogenous ATP Contributes to Superfluous $\left[{ }^{3} \mathbf{H}\right]$ ACh Release in Urothelium-Denuded Detrusor Strips from BPH Patients Via the Activation of P2X2/3 Heterotrimers. Nerve-evoked $\left[{ }^{3} \mathrm{H}\right] \mathrm{ACh}$ release after the first stimulation period $\left(\mathrm{S}_{1}\right)$ expressed as a percentage of the total radioactivity present in the tissue at the beginning of the collection period (fractional release, \%) was 1.5-fold higher
$(P<0.05)$ in urothelium-denuded detrusor strips from $\mathrm{BPH}$ patients $(0.84 \pm 0.03, n=6)$ compared with control subjects (0.55 $\pm 0.02, n=4)$ (Fig. 4; cf. Silva-Ramos et al., 2015). Interestingly, nerve-evoked contractions of detrusor strips from BPH patients (Fig. 1C) also had a higher $(P<0.05)$ magnitude than those observed in control preparations (Fig. 1B); i.e., the maximal detrusor tension elicited by 50$\mathrm{Hz}$ trains normalized by the effect of high extracellular $\mathrm{KCl}$ $(60 \mathrm{mM})$ increased $(P<0.05)$ from $18.3 \% \pm 1.6 \%(n=3)$ in control individuals to $25.9 \% \pm 9.8 \%(n=4)$ in $\mathrm{BPH}$ patients. A similar phenomenon was verified using $10-$ and $20-\mathrm{Hz}$ stimulation trains.

The cholinergic hyperactivity was abrogated after desensitization of ionotropic P2X1-3 receptors with the enzymaticallystable ATP analog $\alpha, \beta$-MeATP $(30 \mu \mathrm{M})$; incubation with $\alpha, \beta$-MeATP $(30 \mu \mathrm{M})$ for 15 minutes reduced by $14 \% \pm$ $6 \%(n=6)$ the release of $\left[{ }^{3} \mathrm{H}\right] \mathrm{ACh}$ from stimulated detrusor strips from control individuals, but this decrease was more evident $(52 \% \pm 7 \%, n=4)$ in BPH patients (Fig. 4). A similar inhibitory response was obtained using PPADS $(10 \mu \mathrm{M})$, which nonselectively blocks P2 purinoceptors; PPADS $(10 \mu \mathrm{M})$ reduced nerve-evoked $\left[{ }^{3} \mathrm{H}\right] \mathrm{ACh}$ release by $6 \% \pm$ $8 \%(n=4)$ and $43 \% \pm 6 \%(n=4)$ in control individuals and $\mathrm{BPH}$ patients, respectively (Fig. 5). 
$\mathbf{A}_{\mathbf{i}}$
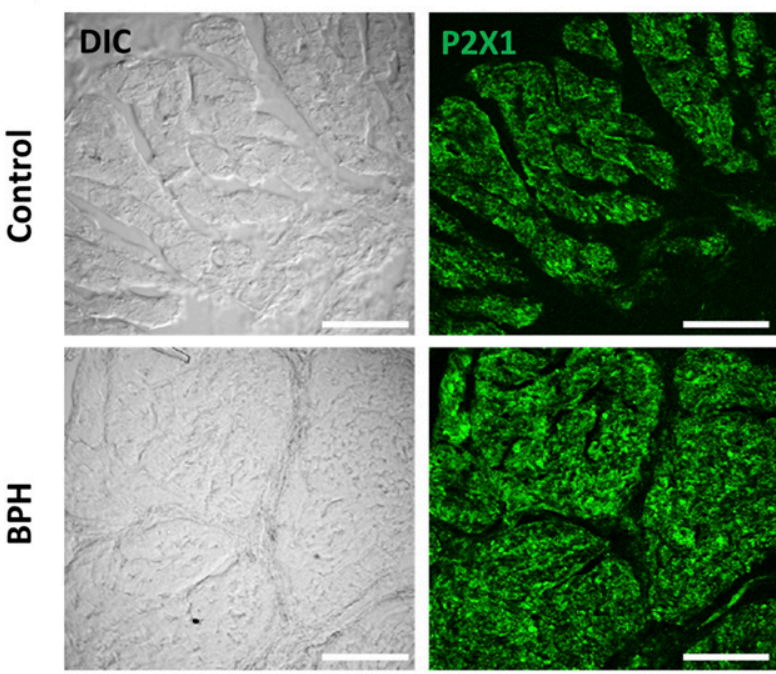

$\mathbf{A}_{\text {ii }}$
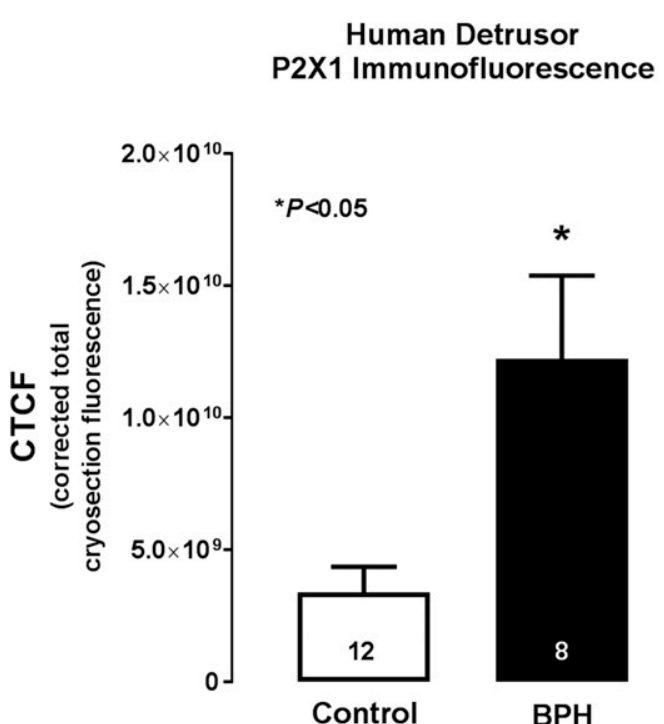

$B_{i i}$

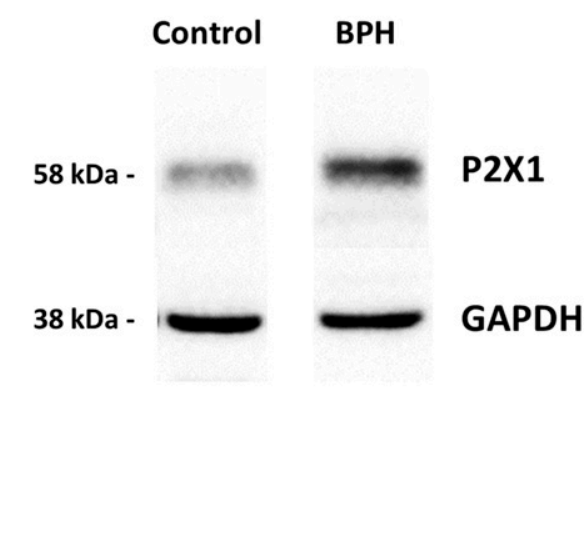

$\mathbf{B}_{\mathrm{iii}}$

\section{Human Detrusor P2X1 Immunoblot Density}

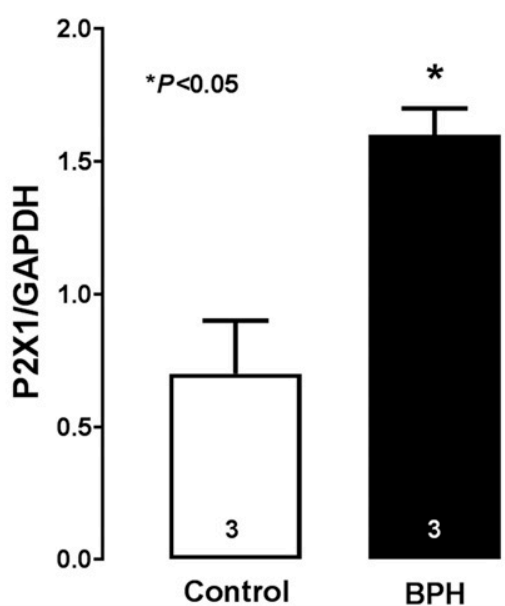

Fig. 3. The $\mathrm{P} 2 \mathrm{X} 1$ receptor is upregulated in urothelium-denuded detrusor strips from BPH patients compared with control organ donors. (A) Confocal micrographs of transverse sections of the human detrusor isolated from control individuals and BPH patients stained with an antibody specific for a highly conserved regions of the P2X1 receptor intracellular C-terminus (APR-001; Alomone). The P2X1 receptor immunoreactivity follows a plasma membrane staining pattern. Differential interference contrast (DIC) micrographs are also shown for comparison. Scale bar, $20 \mu \mathrm{m}$. The bar chart shown in $\left(\mathrm{A}_{\mathrm{ii}}\right)$ represents mean \pm S.D. of corrected total cryosection fluorescence (CTCF) staining for the P2X1 receptor in the detrusor of control individuals and BPH patients. (B) Representative immunoblots of the P2X1 receptor in urothelium-denuded male detrusor homogenates of one control individual and one $\mathrm{BPH}$ patient run in parallel. Gels were loaded with $65 \mu \mathrm{g}$ of protein. The bar chart shown in $\left(\mathrm{B}_{\mathrm{ii}}\right)$ represents mean $\pm \mathrm{S}$.D. of the P2X1 receptor density in control individuals and BPH patients normalized using as a reference protein the highly conserved GAPDH enzyme (EC 1.2.1.12, MW approx. $37 \mathrm{kDa}$ ). The number of individuals per group is shown below each bar. $* P<0.05$ (unpaired Student's $t$-test corrected for multiple comparisons using the Holm-Sidak method) represent significant differences compared with control individuals.

The selective P2X1 antagonist NF023 applied in a concentration $(3 \mu \mathrm{M})$ that was able to prevent ATP-induced contractions of the human detrusor, failed to affect $(P>0.05)$ nerve-evoked $\left[{ }^{3} \mathrm{H}\right] \mathrm{ACh}$ release from detrusor strips isolated either from control individuals or from BPH patients (Fig. 5). Blockage of P2X3 and P2X2/3 receptors with A317491 (100 nM) and TNPATP (10 nM), respectively, lowered by a similar amount the nerve-evoked $\left[{ }^{3} \mathrm{H}\right] \mathrm{ACh}$ release from control detrusor strips. The inhibitory effect of TNP-ATP $(10 \mathrm{nM})$ was much more evident in detrusor samples from BPH patients $(43 \% \pm 6 \%, n=4)$ than from control organ donors $(27 \% \pm 9 \%, n=4)$, whereas the effect of A317491 (100 nM) was kept almost unaltered in the two groups $(24 \% \pm 4 \%, n=5$ in $\mathrm{BPH}$ patients vs. $20 \% \pm 2 \%, n=4$ in controls) (Fig. 5). It is, however, worth noting that A317491 (100 $\mathrm{nM})$ and TNP-ATP $(10 \mathrm{nM})$ were both inactive on ATP-induced human bladder contractions (see Fig. 2).

\section{Discussion and Conclusions}

In a previous study, we showed that cholinergic neurotransmission was increased in mucosal-denuded detrusor strips from $\mathrm{BPH}$ patients compared with control organ donors and that this could have been the result, at least in part, of deficits in the activity of ecto-NTPDase1/CD39 subsequently unbalancing extracellular 
A

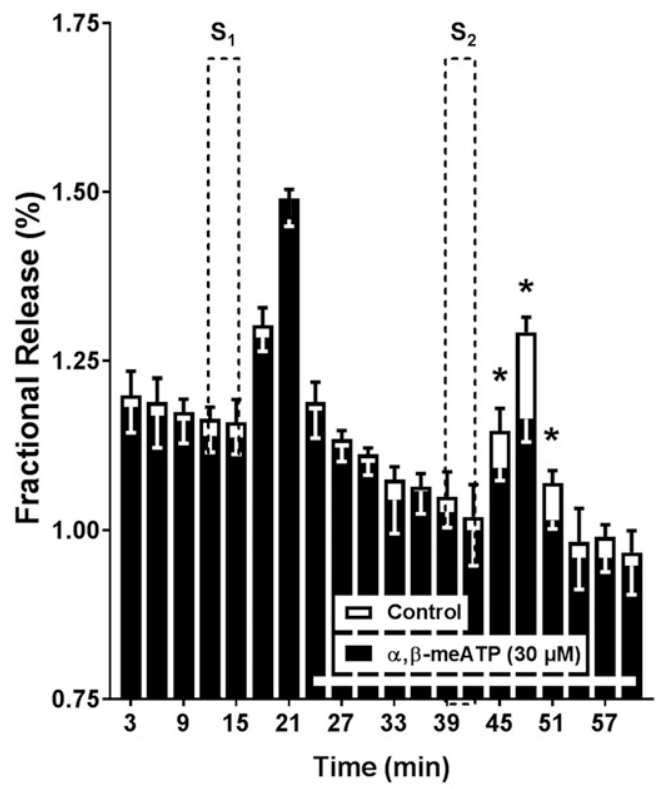

B

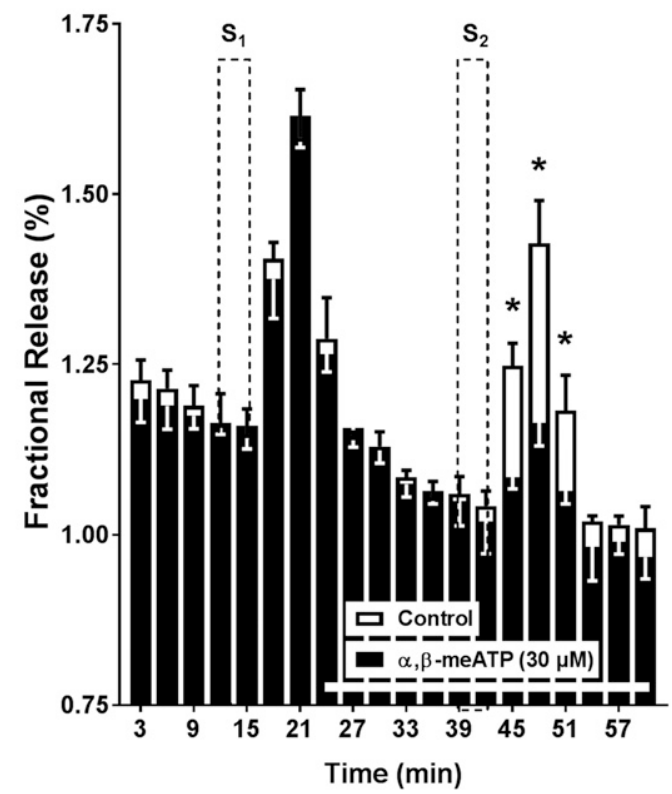

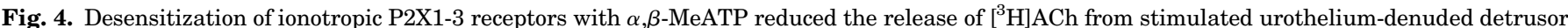

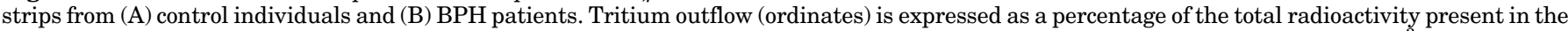

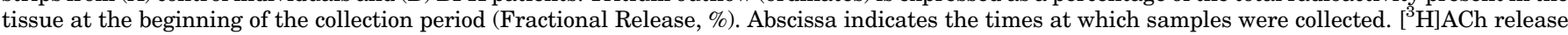

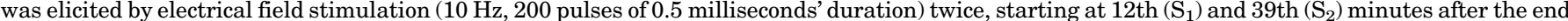

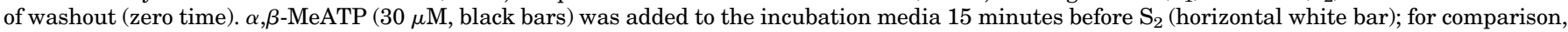

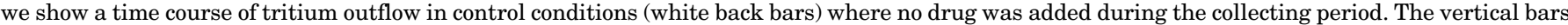

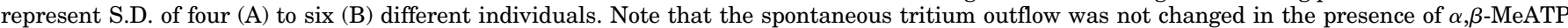

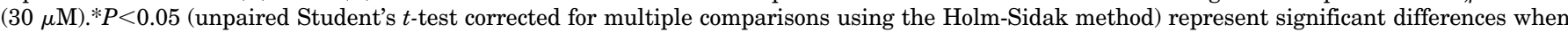
compared to control individuals.

ATP accumulation and endogenous adenosine formation (SilvaRamos et al., 2015). Here, we showed that extracellular ATP accumulation increases detrusor tension in obstructed patients by two synergistic mechanisms. One is mediated through direct activation of ionotropic $\mathrm{P} 2 \mathrm{X} 1$ receptors, which are overexpressed on smooth muscle fibers of obstructed human bladders. The second is operated indirectly through facilitation of $\mathrm{ACh}$ release from cholinergic nerves via the activation of $\mathrm{P} 2 \mathrm{X} 2 / 3$ receptor heterotrimers sensitive: 1) to PPADS, TNP-ATP, and A317491 antagonists and 2) to desensitization by the enzymatically-stable ATP analog $\alpha, \beta$-MeATP. The unbalance between the excessive ATP-mediated P2X2/3 receptor facilitation of $\mathrm{ACh}$ release and the loss of the adenosine $\mathrm{A}_{1}$ receptor-mediated inhibitory tone of cholinergic nerve terminals contributes to increased nerve-evoked detrusor reactivity in obstructed patients with BPH. Although the purinergic-related detrusor overactivity may be a burden for patients with BOO, which is certainly worth being explored therapeutically using P2X receptor antagonists and/or adenosine $\mathrm{A}_{1}$ receptor modulators (e.g., receptor agonists, nucleoside uptake, and deaminase inhibitors), its maintenance/potentiation in later stages of the disease may be attractive to overcome detrusor underactivity. Even though we did not explore this possibility specifically, we could have increased ATP-mediated contractions of detrusor strips from $\mathrm{BPH}$ patients using a competitive inhibitor of human NTPDase1/ CD39, ARL67156 (100 $\mu \mathrm{M})$. Therefore, one can speculate that manipulation of the purinergic tone is even more relevant to overcoming DU, taking into consideration that cholinergic activity is substantially impaired in obstructed patients owing to $\mathrm{BPH}$ (see below).
The effect of $\mathrm{BOO}$ on ACh release from bladder nerves has only been studied in animal models. In a rat model of $\mathrm{BOO}$, nerve-evoked $\mathrm{ACh}$ release (normalized by the wet tissue weight) decreased in parallel to the reduction in the density of bladder nerves (Murakami et al., 2008). Nevertheless, nerve density changes must take into consideration that obstructed bladders exhibit hypertrophy of the smooth muscle fibers and intercellular accumulation of collagen and elastic fibers causing a 4-fold increase in the bladder weight corrected by the total body weight. Therefore, if one corrects the amount of $\mathrm{ACh}$ release by the increase in bladder weight owing to $\mathrm{BOO}$ in the Murakami study, we easily reach the conclusion that the absolute amount of ACh release triggered by electrical stimulation is similar (or even higher) in obstructed than in control bladders, and the same certainly occurs with the number of nerves innervating the bladder of the two animal groups. More importantly, experimental evidence supports the idea that animal models of BOO do not exactly mimic the pathologic features observed in obstructed bladders of men with $\mathrm{BPH}$. Whereas $\mathrm{BOO}$ causes very rapidly rigid bladders in animal models, the bladder of obstructed $\mathrm{BPH}$ patients is fairly flexible and rigidity is progressive and usually takes several years. The bladder mass of BPH patients increases slowly and hardly doubles the original weight (Kojima et al., 1996), which is far from the 4 -fold increase in the bladder weight gain observed 2 weeks after surgery to partially occlude the bladder outlet in the rat (Murakami et al., 2008; see also Hampel et al., 2002). Rapid development of smooth muscle hypertrophy and interstitial fibrosis: 1) supports the inverse relationship between detrusor contractility and the 
Human Detrusor

$\left[{ }^{3} \mathrm{H}\right] \mathrm{ACh}$ release

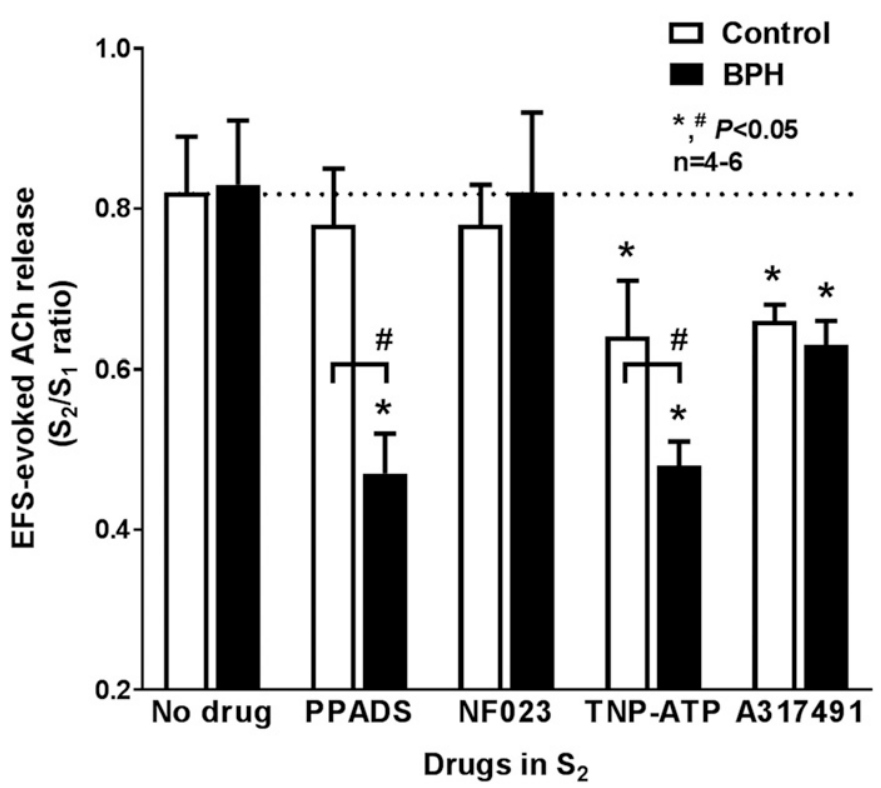

Fig. 5. Tonic activation of $\mathrm{P} 2 \mathrm{X} 2 / 3$ heterotrimers downregulates superfluous $\left[{ }^{3} \mathrm{H}\right] \mathrm{ACh}$ release from cholinergic nerves innervating the detrusor of BPH patients. PPADS (10 $\mu \mathrm{M}$, a nonselective P2 antagonist), NF023 (3 $\mu \mathrm{M}$, a selective P2X1 antagonist), TNP-ATP (10 nM, a preferential P2X2/3 antagonist), and A317491 (100 nM, a selective P2X3 antagonist) were applied 15 minutes before $\mathrm{S}_{2}$. The ordinates are $\mathrm{S}_{2} / \mathrm{S}_{1}$ ratios, i.e., the ratio between the amount of tritium collected during the second period of stimulation and that obtained during the first stimulation period when no drug was added; the $\mathrm{S}_{2} / \mathrm{S}_{1}$ ratios obtained in the absence of any drug are also shown from comparison (left-hand side bars). The data are means \pm S.D. of four to six individuals. ${ }^{*}, P<0.05$ (two-way ANOVA followed by the Sidak's multicomparison test with a single pooled variance) represent significant differences compared with the situation in which no drug was added or with the effect of the same drug in control individuals, respectively. ${ }^{*} \mathrm{P}<0.05$ (two-way ANOVA followed by the Sidak's multicomparison test with a single pooled variance) represent significant differences when compared to the situation where no drug was added; ${ }^{\#} \mathrm{P}<0.05$ (two-way ANOVA followed by the Sidak's multicomparison test with a single pooled variance) represent significant differences when compared to the effect of the same drug in control individuals.

degree of outlet obstruction in these animals (Moore et al., 2002; Austin et al., 2004) and 2) may explain why the detrusor decompensates so early in the course of experimental obstruction (Michel and Barendrecht, 2008), a situation that is observed only at later stages of the human disease.

Previous studies using obstructed human bladder samples admitted that this pathologic condition was associated with a partial bladder denervation compared with control specimens (Harrison et al., 1987; Gosling, 1997). Unfortunately, these authors did not directly assess cholinergic innervation of the human bladder and, more importantly, they also failed to actually measure bladder denervation, i.e., the reduction in the number of nerve fibers. As argued above regarding animal studies, a decrease in the density of nerve fibers within the bladder wall is not an index of bladder denervation, because one must take into account smooth muscle hypertrophy and more or less extensive interstitial deposition of extracellular matrix proteins (e.g., collagen, elastin), which moves apart nerve fibers and tiny axon terminals. The partial denervation hypothesis was sustained by functional studies showing that muscle biopsies from patients with detrusor instability owing to BOO demonstrated supersensitivity to $\mathrm{ACh}$ and a reduction in nerve-mediated responses compared with stable bladders (Harrison et al., 1987). Yet, in this respect, functional studies are not consensual (Turner and Brading, 1997; Michel and Barendrecht, 2008). We are aware that discrepancies among detrusor responsiveness to $\mathrm{ACh}$ in $\mathrm{BPH}$ - versus controlpatients may be a consequence of age differences between the two groups (Yoshida et al., 2001; Mansfield et al., 2005). Here, we excluded this possibility, because no significant correlation between age and the magnitude of ACh-induced detrusor contractions was observed.

Notwithstanding this dispute, we found that electrical field stimulation of urothelium-denuded detrusor strips from obstructed $\mathrm{BPH}$ patients releases higher amounts of $\left[{ }^{3} \mathrm{H}\right] \mathrm{ACh}$ compared with controls. Thus, if the partial denervation hypothesis is confirmed, our data suggest that the amount of ACh released per nerve unit must be highly enhanced in the bladder of BPH patients. Interestingly, we also showed here that the amplitude of ACh-induced contractions was significantly reduced in obstructed BPH bladders compared with controls, a situation similar to that observed regarding carbachol-induced contractions in rats tested 6 months after surgery to cause BOO (Murakami et al., 2008). Reduction in cholinergic sensitivity of detrusor smooth muscle fibers would attenuate, rather than increase, nerve-evoked contractions of obstructed human bladders. To explain neurotransmission strengthening in the obstructed human detrusor, one must take into account reinforcement of the purinergic component leading: 1) to the release of excessive amounts of ACh from cholinergic nerve efferents, and/or 2) to the activation of overexpressed P2X1 receptors on detrusor smooth muscle fibers by released ATP.

Data from our study suggest that anticholinergic agents may be less effective in treating detrusor overactivity in BPH patients. Since the majority of these compounds are competitive muscarinic antagonists preferentially blocking $\mathrm{M}_{3}$ receptors on smooth muscle fibers, their action may be substantially hampered in obstructed $\mathrm{BPH}$ patients because ACh release is facilitated, leading: 1) to superfluous levels of the transmitter in the synaptic cleft, and/or 2) to muscarinic receptor desensitization by excessive cholinergic exposure, as has been demonstrated in the rat BOO model (Braverman and Ruggieri, 2003). It thus appears that the net cholinergic neurotransmission in obstructed bladders from $\mathrm{BPH}$ patients is partially compensated by the increase in $\mathrm{ACh}$ release from cholinergic nerve terminals, but this does not fully explain detrusor overactivity often seen in BPH patients unless one hypothesizes the release/accumulation of a second extracellular transmitter, like ATP, being responsible for increasing the activity of cholinergic nerve terminals and/or the detrusor contraction. According to this theory, blockage of purinergic signals may be a valuable alterative for the treatment of detrusor overactivity in $\mathrm{BPH}$ patients resistant to antimuscarinics.

The role of ATP in the process of enhancing detrusor contraction in obstructed patients seems pivotal. ATP has long been considered a "danger-signaling molecule" in many organ systems and the nucleotide undertakes important roles in tissue remodeling secondary to injury (Burnstock and Verkhratsky, 2010). The exact mechanism by which the purinergic signaling cascade is activated in the detrusor of BPH patients is not yet established. There is a considerable bulk of evidence showing that BOO causes tissue ischemia (Azadzoi et al., 1996; Saito et al., 1997; Belenky et al., 2003; 
Yamaguchi et al., 2014) and this may trigger the release of purines from affected cells. Experimentally-induced ischemia secondary to hypoxia-reoxygenation cycles increases atropine-resistant nerve-mediated contractions in the rat detrusor, an effect that can be blocked by $\mathrm{P} 2 \mathrm{X}$ receptor antagonists (Elliott et al., 2013). Furthermore, ischemia lowers tissue $\mathrm{pH}$, which is usually associated with deficits in the activity of NTPDases leading to extracellular ATP accumulation (Kukulski et al., 2005) along with the upregulation of ionotropic $\mathrm{P} 2 \mathrm{X}$ receptor expression and activity (Zhang et al., 2014). Summation of acidic pH and painful purinergic signals have recently been demonstrated to occur via unilateral interaction between acid-sensing ion channels (e.g., ASIC3) and ATP-sensitive P2X3 receptor protein complexes through stimulation of the proton-binding site and downstream activation of $\mathrm{Ca}^{2+}$-dependent pathways (Stephan et al., 2018), but the presence of such complexes has not been documented yet in the human bladder. Although we did not address these issues in this study, ischemia-induced purinergic signaling reinforcement may be a mechanism worth exploring in the future to explain the pathophysiology of detrusor overactivity in $\mathrm{BPH}$ patients.

This study showed for the first time that endogenously released ATP facilitates ACh outflow from urothelium-denuded human detrusor strips and this effect seems to be strengthened in obstructed bladders of BPH patients. Facilitation of ACh release by ATP has been previously shown in other synapses (Magalhães-Cardoso et al., 2003; Sperlágh et al., 2007). Our results suggest that ATP-mediated facilitation of ACh release is dependent on the activation of ionotropic P2X1-3 receptors, as these receptor subtypes are only amenable to desensitization by $\alpha, \beta$-methylene ATP. Similar results were obtained in the porcine detrusor (D'Agostino et al., 2012). In contrast to the well known contractile effect of ATP in the human detrusor via activation of the P2X1 receptor, this receptor subtype failed to participate in ATP neuromodulation. This was concluded because the selective P2X1 receptor antagonist NF023 was devoid of effect on nerveevoked ACh release from detrusor strips of control organ donors and $\mathrm{BPH}$ patients. Blockage of $\mathrm{P} 2 \mathrm{X} 2 / 3$ heterotrimers with TNPATP, as well of the P2X3 receptor with its selective antagonist, A317491, significantly decreased the release of ACh from stimulated detrusor strips of control individuals. Interestingly, the inhibitory effect of TNP-ATP almost doubled its magnitude in samples collected from obstructed $\mathrm{BPH}$ patients, whereas the effect resulting from selectively blocking the P2X3 receptor with A317491 remained unaltered. These findings suggest that both $\mathrm{P} 2 \mathrm{X} 2 / 3$ and $\mathrm{P} 2 \mathrm{X} 3$ receptors may be involved in ATP-mediated facilitation of nerve-evoked ACh in the human bladder, but augmentation of the purinergic neuromodulatory tone in obstructed bladders of $\mathrm{BPH}$ patients may result from upregulation of the $\mathrm{P} 2 \mathrm{X} 2 / 3$ receptor subtype. The presence of P2X3 receptors and P2X2/3 heterotrimers has been detected in peripheral nerves by immunofluorescence microscopy (Dunn et al., 2001). These receptors have been found in suburothelium nerve fibers of the human bladder (Brady et al., 2004) and their presence was also detected in nerve bundles of rat and human detrusors (Lee et al., 2000; Neuhaus et al., 2012).

In conclusion, data produced here and in previous studies support the idea that in obstructed bladders of BPH patients several mechanisms are activated toward the generation of stronger nerve-evoked detrusor contractions. These include: 1) deficits in extracellular ATP hydrolysis leading to 2) increased contractile responses mediated by overexpressed postjunctional $\mathrm{P} 2 \mathrm{X} 1$ receptors, 3 ) activation of facilitatory $\mathrm{P} 2 \mathrm{X} 2 / 3$ heterotrimers and decreased adenosine $\mathrm{A}_{1}$-receptor-mediated inhibitory tonus on cholinergic nerves that result in 4) facilitation of ACh release from stimulated nerve terminals, which is 5) partial compensation for the lack of sensitivity of cholinoceptors present on smooth muscle fibers. Recent publications have pointed out that P2X3 (and/or P2X2/3) antagonists could be potential candidates for the treatment of painful bladder and overactive bladder syndromes (Ford and Undem, 2013; Smith et al., 2013). Besides demonstrating the relevance of $\mathrm{P} 2 \mathrm{X} 3$ receptors in mediating bladder sensations, our data add important information concerning their effect on cholinergic neuroexcitability and detrusor overactivity that must be also taken into consideration. Our results also shed light on possible ways to increase bladder performance in situations of detrusor underactivity resulting from BOO. At present there is no pharmacological treatment of detrusor underactivity, and this is a clear unmet medical need (Osman et al., 2014). It is an appealing prospect to enhance detrusor performance in these patients through the activation of presynaptic $\mathrm{P} 2 \mathrm{X} 2 / 3$ receptors, either by using subtype-specific receptor agonists or by inhibiting the activity of NTPDase1/CD39, as we did with ARL67156.

\section{Acknowledgments}

The authors thank Mrs. Helena Costa e Silva and Belmira Silva for their technical assistance.

\section{Authorship Contributions}

Participated in research design: Silva-Ramos, Silva, Faria, Ferreirinha, Correia-de-Sá.

Conducted experiments: Silva-Ramos, Silva, Faria, Ferreirinha, Correia-de-Sá.

Contributed new reagents or analytic tools: Correia-de-Sá.

Performed data analysis: Silva-Ramos, Silva, Faria, Ferreirinha, Correia-de-Sá.

Wrote or contributed to the writing of the manuscript: Silva-Ramos, Silva, Ferreirinha, Correia-de-Sá.

\section{References}

Abrams PH, Farrar DJ, Turner-Warwick RT, Whiteside CG, and Feneley RC (1979) The results of prostatectomy: a symptomatic and urodynamic analysis of 152 patients. J Urol 121:640-642.

Andersson KE (2003) Storage and voiding symptoms: pathophysiologic aspects. Urology 62:3-10.

Austin JC, Chacko SK, DiSanto M, Canning DA, and Zderic SA (2004) A male murine model of partial bladder outlet obstruction reveals changes in detrusor morphology, contractility and Myosin isoform expression. J Urol 172:1524-1528.

Azadzoi KM, Pontari M, Vlachiotis J, and Siroky MB (1996) Canine bladder blood flow and oxygenation: changes induced by filling, contraction and outlet obstruction. J Urol 155:1459-1465.

Banks FC, Knight GE, Calvert RC, Morgan RJ, and Burnstock G (2006) Alterations in purinergic and cholinergic components of contractile responses of isolated detrusor contraction in a rat model of partial bladder outlet obstruction. BJU Int 97:372-378.

Barros-Barbosa AR, Fonseca AL, Guerra-Gomes S, Ferreirinha F, Santos A, Rangel R, Lobo MG, Correia-de-Sá P, and Cordeiro JM (2016) Up-regulation of P2X7 receptormediated inhibition of GABA uptake by nerve terminals of the human epileptic neocortex. Epilepsia 57:99-110.

Barros-Barbosa AR, Oliveira Â, Lobo MG, Cordeiro JM, and Correia-de-Sá P (2018) Under stressful conditions activation of the ionotropic P2X7 receptor differentially regulates GABA and glutamate release from nerve terminals of the rat cerebral cortex. Neurochem Int 112:81-95.

Bayliss M, Wu C, Newgreen D, Mundy AR, and Fry CH (1999) A quantitative study of atropine-resistant contractile responses in human detrusor smooth muscle, from stable, unstable and obstructed bladders. J Urol 162:1833-1839.

Belenky A, Abarbanel Y, Cohen M, Yossepowitch O, Livne PM, and Bachar GN (2003) Detrusor resistive index evaluated by Doppler ultrasonography as a potential indicator of bladder outlet obstruction. Urology 62:647-650.

Brady CM, Apostolidis A, Yiangou Y, Baecker PA, Ford AP, Freeman A, Jacques TS, Fowler CJ, and Anand P (2004) P2X3-immunoreactive nerve fibres in neurogenic detrusor overactivity and the effect of intravesical resiniferatoxin. Eur Urol 46: 247-253.

Braverman AS and Ruggieri MR Sr (2003) Hypertrophy changes the muscarinic receptor subtype mediating bladder contraction from $\mathrm{M}_{3}$ toward $\mathrm{M}_{2}$. Am J Physiol Regul Integr Comp Physiol 285:R701-R708. 
Burnstock G (2011) Therapeutic potential of purinergic signalling for diseases of the urinary tract. BJU Int 107:192-204.

Burnstock G and Verkhratsky A (2010) Long-term (trophic) purinergic signalling: purinoceptors control cell proliferation, differentiation and death. Cell Death Dis 1:e9. Carneiro I, Timóteo MA, Silva I, Vieira C, Baldaia C, Ferreirinha F, Silva-Ramos M, and Correia-de-Sá $\mathrm{P}$ (2014) Activation of $\mathrm{P}^{2} \mathrm{Y}_{6}$ receptors increases the voiding frequency in anaesthetized rats by releasing ATP from the bladder urothelium. $\mathrm{Br}$ J Pharmacol 171:3404-3419.

D’Agostino G, Condino AM, Calvi V, Boschi F, Gioglio L, and Barbieri A (2012) Purinergic P2X3 heteroreceptors enhance parasympathetic motor drive in isolated porcine detrusor, a reliable model for development of P2X selective blockers for detrusor hyperactivity. Pharmacol Res 65:129-136.

Duarte-Araújo M, Nascimento C, Timoteo MA, Magalhães-Cardoso MT, and Correiade-Sá P (2009) Relative contribution of ecto-ATPase and ecto-ATPDase pathways to the biphasic effect of ATP on acetylcholine release from myenteric motoneurons. $\mathrm{Br}$ $J$ Pharmacol 156:519-533.

Dunn PM, Zhong Y, and Burnstock G (2001) P2X receptors in peripheral neurons. Prog Neurobiol 65:107-134.

Elliott RA, Tonnu A, Ghaffar N, Taylor AH, Tincello DG, and Norman RI (2013) Enhanced purinergic contractile responses and P2X1 receptor expression in detrusor muscle during cycles of hypoxia-glucopenia and reoxygenation. Exp Physiol 98: 1683-1695.

Elneil S, Skepper JN, Kidd EJ, Williamson JG, and Ferguson DR (2001) Distribution of $\mathrm{P} 2 \mathrm{X}(1)$ and $\mathrm{P} 2 \mathrm{X}(3)$ receptors in the rat and human urinary bladder. Pharmacology 63:120-128.

Ford AP, Gever JR, Nunn PA, Zhong Y, Cefalu JS, Dillon MP, and Cockayne DA (2006) Purinoceptors as therapeutic targets for lower urinary tract dysfunction. $\mathrm{Br}$ $J$ Pharmacol 147 (Suppl 2):S132-S143.

Ford AP and Undem BJ (2013) The therapeutic promise of ATP antagonism at P2X3 receptors in respiratory and urological disorders. Front Cell Neurosci 7:267.

Fry CH, Wu C, and Mundy AR (1999) Bladder instability and detrusor smooth muscle function. Exp Physiol 84:161-169.

Gosling JA (1997) Modification of bladder structure in response to outflow obstruction and ageing. Eur Urol 32 (Suppl 1):9-14.

Hampel C, Dolber PC, Smith MP, Savic SL, Th roff JW, Thor KB, and Schwinn DA (2002) Modulation of bladder alpha1-adrenergic receptor subtype expression by bladder outlet obstruction. J Urol 167:1513-1521.

Harrison SC, Hunnam GR, Farman P, Ferguson DR, and Doyle PT (1987) Bladder instability and denervation in patients with bladder outflow obstruction. Br J Urol 60:519-522.

Harvey RA, Skennerton DE, Newgreen D, and Fry CH (2002) The contractile potency of adenosine triphosphate and ecto-adenosine triphosphatase activity in guinea pig detrusor and detrusor from patients with a stable, unstable or obstructed bladder. J Urol 168:1235-1239.

King JA, Huddart H, and Staff WG (1997) Purinergic modulation of rat urinary bladder detrusor smooth muscle. Gen Pharmacol 29:597-604.

Kojima M, Inui E, Ochiai A, Naya Y, Ukimura O, and Watanabe H (1996) Ultrasonic estimation of bladder weight as a measure of bladder hypertrophy in men with infravesical obstruction: a preliminary report. Urology 47:942-947.

Kukulski F, Lévesque SA, Lavoie EG, Lecka J, Bigonnesse F, Knowles AF, Robson SC Kirley TL, and Sévigny J (2005) Comparative hydrolysis of P2 receptor agonists by NTPDases 1, 2, 3 and 8. Purinergic Signal 1:193-204.

Lee HY, Bardini M, and Burnstock G (2000) Distribution of P2X receptors in the urinary bladder and the ureter of the rat. J Urol 163:2002-2007.

Magalhães-Cardoso MT, Pereira MF, Oliveira L, Ribeiro JA, Cunha RA, and Correia-deSá P (2003) Ecto-AMP deaminase blunts the ATP-derived adenosine A2A receptor facilitation of acetylcholine release at rat motor nerve endings. $J$ Physiol 549:399-408.

Mansfield KJ, Liu L, Mitchelson FJ, Moore KH, Millard RJ, and Burcher E (2005) Muscarinic receptor subtypes in human bladder detrusor and mucosa, studied by radioligand binding and quantitative competitive RT-PCR: changes in ageing. $\mathrm{Br}$ J Pharmacol 144:1089-1099.

Michel MC and Barendrecht MM (2008) Physiological and pathological regulation of the autonomic control of urinary bladder contractility. Pharmacol Ther 117:297-312.

Mirone V, Imbimbo C, Longo N, and Fusco F (2007) The detrusor muscle: an innocent victim of bladder outlet obstruction. Eur Urol 51:57-66.

Moore CK, Levendusky M, and Longhurst PA (2002) Relationship of mass of obstructed rat bladders and responsiveness to adrenergic stimulation. J Urol 168: $1621-1625$

Murakami S, Yoshida M, Masunaga K, Maeda Y, and Ueda S (2008) Change in acetylcholine release from rat bladder with partial outlet obstruction. BJU Int 101: 633-639.
Neuhaus J, Schulte-Baukloh H, Stolzenburg JU, Speroni di Fenizio P, Horn LC, Rüffert H, Hartenstein S, Burger M, Schulze M, and Schwalenberg T (2012) Individual receptor profiling as a novel tool to support diagnosis of bladder pain syndrome/interstitial cystitis (BPS/IC). World J Urol 30:693-700.

O'Reilly BA, Kosaka AH, Chang TK, Ford AP, Popert R, and McMahon SB (2001) A quantitative analysis of purinoceptor expression in the bladders of patients with symptomatic outlet obstruction. BJU Int 87:617-622.

Osman NI, Chapple CR, Abrams P, Dmochowski R, Haab F, Nitti V, Koelbl H, van Kerrebroeck P, and Wein AJ (2014) Detrusor underactivity and the underactive bladder: a new clinical entity? A review of current terminology, definitions, epidemiology, aetiology, and diagnosis. Eur Urol 65:389-398.

Ribeiro JA, Cunha RA, Correia-de-Sá P, and Sebastião AM (1996) Purinergic regulation of acetylcholine release. Prog Brain Res 109:231-241.

Saito M, Yokoi K, Ohmura M, and Kondo A (1997) Effects of partial outflow obstruction on bladder contractility and blood flow to the detrusor: comparison between mild and severe obstruction. Urol Int 59:226-230.

Silva I, Costa AF, Moreira S, Ferreirinha F, Magalhães-Cardoso MT, Calejo I, SilvaRamos M, and Correia-de-Sá P (2017) Inhibition of cholinergic neurotransmission by $\beta_{3}$-adrenoceptors depends on adenosine release and $\mathrm{A}_{1}$-receptor activation in human and rat urinary bladders. Am J Physiol Renal Physiol 313:F388-F403.

Silva-Ramos M, Silva I, Duarte-Araújo M, Magalhães-Cardoso T, Lafuente-de-Carvalho J, and Correia-de-Sá P (2010) Loss of balance between excitatory P2X3 and inhibitory A1 receptors contribute to cholinergic hyperactivity in obstructed human bladder. Basic Clin Pharmacol Toxicol 107 (Suppl s1):2397.

Silva-Ramos M, Silva I, Faria M, Magalhães-Cardoso MT, Correia J, Ferreirinha F, and Correia-de-Sá P (2015) Impairment of ATP hydrolysis decreases adenosine A1 receptor tonus favoring cholinergic nerve hyperactivity in the obstructed human urinary bladder. Purinergic Signal 11:595-606.

Sjögren C, Andersson KE, Husted S, Mattiasson A, and Moller-Madsen B (1982) Atropine resistance of transmurally stimulated isolated human bladder muscle. $J$ Urol 128:1368-1371.

Smith SA, Black D, Song D, and Ford AP (2013) A novel method to estimate AF-219 levels in bladder interstitium derived from drug excreted into the urine. FASEB $J$ 27:1103.

Sperlágh B, Heinrich A, and Csölle C (2007) P2 receptor-mediated modulation of neurotransmitter release-an update. Purinergic Signal 3:269-284.

Stephan G, Huang L, Tang Y, Vilotti S, Fabbretti E, Yu Y, Nörenberg W, Franke H, Gölöncsér F, Sperlágh B, et al. (2018) The ASIC3/P2X3 cognate receptor is a painrelevant and ligand-gated cationic channel. Nat Commun 9:1354.

Turner WH and Brading AF (1997) Smooth muscle of the bladder in the normal and the diseased state: pathophysiology, diagnosis and treatment. Pharmacol Ther $\mathbf{7 5}$ $77-110$.

van Koeveringe GA, Vahabi B, Andersson KE, Kirschner-Herrmans R, and Oelke M (2011) Detrusor underactivity: a plea for new approaches to a common bladder dysfunction. Neurourol Urodyn 30:723-728.

Van Mastrigt R and Rollema HJ (1992) The prognostic value of bladder contractility in transurethral resection of the prostate. J Urol 148:1856-1860.

Vieira C, Ferreirinha F, Magalhães-Cardoso MT, Silva I, Marques P, and Correia-deSá P (2017) Post-inflammatory ileitis induces non-neuronal purinergic signaling adjustments of cholinergic neurotransmission in the myenteric plexus. Front Pharmacol 8:811.

Wust M, Averbeck B, Reif S, Brater M, and Ravens U (2002) Different responses to drugs against overactive bladder in detrusor muscle of pig, guinea pig and mouse. Eur $J$ Pharmacol 454:59-69.

Yamaguchi O, Nomiya M, and Andersson KE (2014) Functional consequences of chronic bladder ischemia. Neurourol Urodyn 33:54-58.

Yokota T and Yamaguchi O (1996) Changes in cholinergic and purinergic neurotransmission in pathologic bladder of chronic spinal rabbit. J Urol 156:1862-1866. Yoshida M, Homma Y, Inadome A, Yono M, Seshita H, Miyamoto Y, Murakami S Kawabe K, and Ueda S (2001) Age-related changes in cholinergic and purinergic neurotransmission in human isolated bladder smooth muscles. Exp Gerontol 36: 99-109.

Zhang Q, Siroky M, Yang JH, Zhao Z, and Azadzoi K (2014) Effects of ischemia and oxidative stress on bladder purinoceptors expression. Urology 84:1249.e1-7.

Address correspondence to: Dr. P. Correia-de-Sá, Laboratório de Farmacologia e Neurobiologia/MedInUP, Instituto de Ciências Biomédicas de Abel Salazar (ICBAS) - Universidade do Porto (UP), R. Jorge Viterbo Ferreira, 228, 4050-313 Porto, Portugal. E-mail: farmacol@icbas.up.pt 